\title{
Research of impact of kind resuperheat and structure of system regenerative feed water to thermodynamic efficiency of cycle with steam- coolant reactor
}

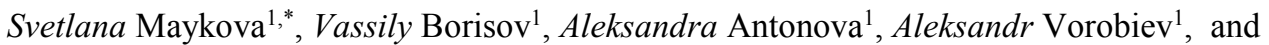 \\ Alexey Abramovskikh ${ }^{1}$ \\ ${ }^{1}$ National Research Tomsk Polytechnic University, 634050 Tomsk, Russia
}

\begin{abstract}
The first key problems of modern nuclear reactors are inability of closed nuclear cycle, problems with spent nuclear fuel, poor effectiveness of nuclear fuel and heat-exchange equipment usage. Dealing with problems consists in usage of fast-neutron reactors with steam coolant. Scientific men analyzed neutron-physical processes in steamcooled fast reactor and consulted that creation of the reactor is viable. In consequence of low steam activation a single-loop steam cycle may be create. The cycle is easy and fool-proof. Core thermomechanical equipment has mastered and has relatively low metal content. Results of calculation are showing that nuclear unit with steam-coolant fast neutron reactor is more efficient than widely used unit with reactor VVER. Usage of simple scheme with four regenerative feedwater heaters the absolute efficiency ratio is more than $43 \%$.
\end{abstract}

\section{Introduction}

Currently, work is underway to improve the efficiency of power plants in General and its separate elements [1-4]. For analyze of thermodynamic efficiency of the single-loop nuclear power plant unit with steam-cooled fast reactor we must to calculate of plant cycle arrangement with variable types of resuperheat and contrasting characteristics and structure of regenerative feedwater heating.

Active zone of the reactor is cooled by dint of superheated steam. Feed water enters in ejectors with the aid of feedpumps. Ejectors are necessary for dispersal of feed-water and mixed it with steam from active zone [1]. Slightly overheated steam enters in reactor active zone where the steam is heated up to high temperature. At reactor outlet the overheat steam is divided into two parts: the first part is going to ejectors as coolant and the second part is sent to a turbine. There are different kinds of steam resuperheat.

\subsection{Bled steam reheating}

\footnotetext{
* Corresponding author: anton@,tpu.ru
} 
Steam from reactor comes in high-pressure casing, depresses to $10 \mathrm{MPa}$ and then it is divided to two streams: the first stream comes in reheated like as coolant, condense and is sent to feedwater system, the second stream depresses to output pressure of the highpressure cylinder, comes in reheated like as heated medium and then comes in low-pressure cylinder. After reheater the main stream has temperature less then temperature at saturation point by superheater approach. However, extra-work in turbine can be obtained into the reheating scheme. Thermal efficiency grows at $1-2 \%$.

\subsection{Superheated steam reheating}

Steam from reactor is divided to two streams: the first stream comes in reheated like as coolant, condense and is sent to feedwater system, the second stream comes in highpressure casing, depresses to output pressure of the high-pressure cylinder, comes in reheated like as heated medium and then comes in low-pressure cylinder. After reheater the main stream has temperature less then temperature at saturation point by superheater approach. Nevertheless, heat efficiency is bigger (2-3\%) then in (a) because the coolant has a higher pressure.

\section{3 "Gas" reheating}

Steam from reactor is comes in high-pressure casing, depresses to output pressure of the high-pressure cylinder and then the steam again comes in reactor, where temperature is rising to inlet temperature. After that the main stream comes in low-pressure cylinder. The kind of reheating has main advantage- high heat efficiency, but the scheme has disadvantages: very long pipelines, energy dissipation in the pipelines, complex reactor design.

\section{Method}

Analysis is based on method of relative discharges [3], where steam discharge for turbine is equal 1 .

Method of the relative flow rate: flow rates of steam, condensate water and water are found like a part of steam flow rate to turbine which is found from energy equation for turbine.

Allowances:

- hydraulic resistance of pipelines is absent;

- regenerative feedwater heaters are open heaters;

Effect of final moisture content is made provision.

Table 1. Design conditions.

\begin{tabular}{|c|c|}
\hline Conditions & Magnitude \\
\hline Initial pressure $\mathrm{P}_{0}, \mathrm{MPa}$ & 13 \\
\hline Initial temperature $\mathrm{t}_{0},{ }^{\circ} \mathrm{C}$ & 555 \\
\hline Condenser backpressure $\mathrm{p}_{\mathrm{k}}, \mathrm{MPa}$ & 0.0045 \\
\hline Steam temperature after reheater, $\mathrm{t}_{\mathrm{r},},{ }^{\circ} \mathrm{C}:$ \\
\hline Bled steam reheating & 296 \\
\hline Superheated steam reheating & 316 \\
\hline "Gas" reheating & 555 \\
\hline Efficiency ratio of turbine for superheated steam area, $\eta_{\mathrm{oi}}$ & 0.87 \\
\hline Maximum allowed final moisture content, $\%$ & 10 \\
\hline
\end{tabular}




\section{Results}

At the result of calculation characteristic curves of thermodynamic efficiency have plotted:

1. Characteristic curves of absolute efficiency ratio of cycle from output pressure of the high-pressure cylinder.

2. Characteristic curves of final moisture content from output pressure of the highpressure cylinder.

3. Characteristic curves of absolute efficiency ratio of cycle from number of regenerative feedwater heaters.

\subsection{Characteristic curves of absolute efficiency ratio of cycle from output pressure of the high-pressure cylinder}

The calculation was made for pressure range from $0.3 \mathrm{MPa}$ to $1.35 \mathrm{MPa}$ with step 0.15 $\mathrm{MPa}$ (fig. 1).

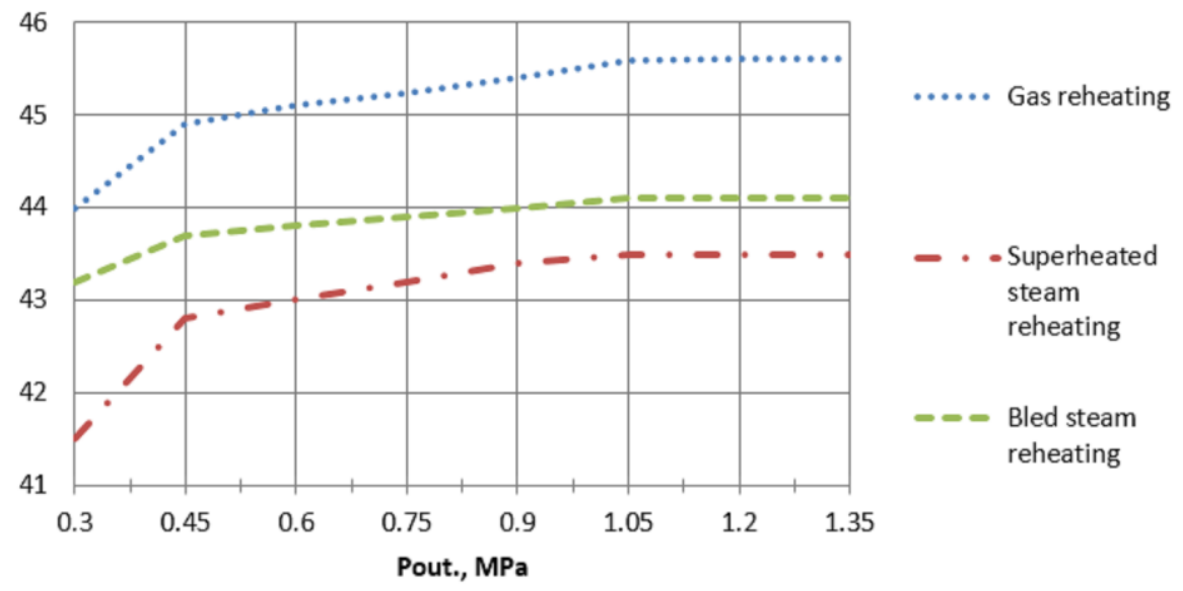

Fig. 1. Characteristic curves of absolute efficiency ratio of cycle from output pressure of the highpressure cylinder.

The characteristic curves have nonlinear dependence. The most intensive increase of absolute efficiency ratio is in range from $0.3 \mathrm{MPa}$ to $0.75 \mathrm{MPa}$. This is because with increasing of output pressure of the high-pressure cylinder heat amount is decreased (final temperature of resuperheat is constant). Post increase of the pressure is ineffective. 


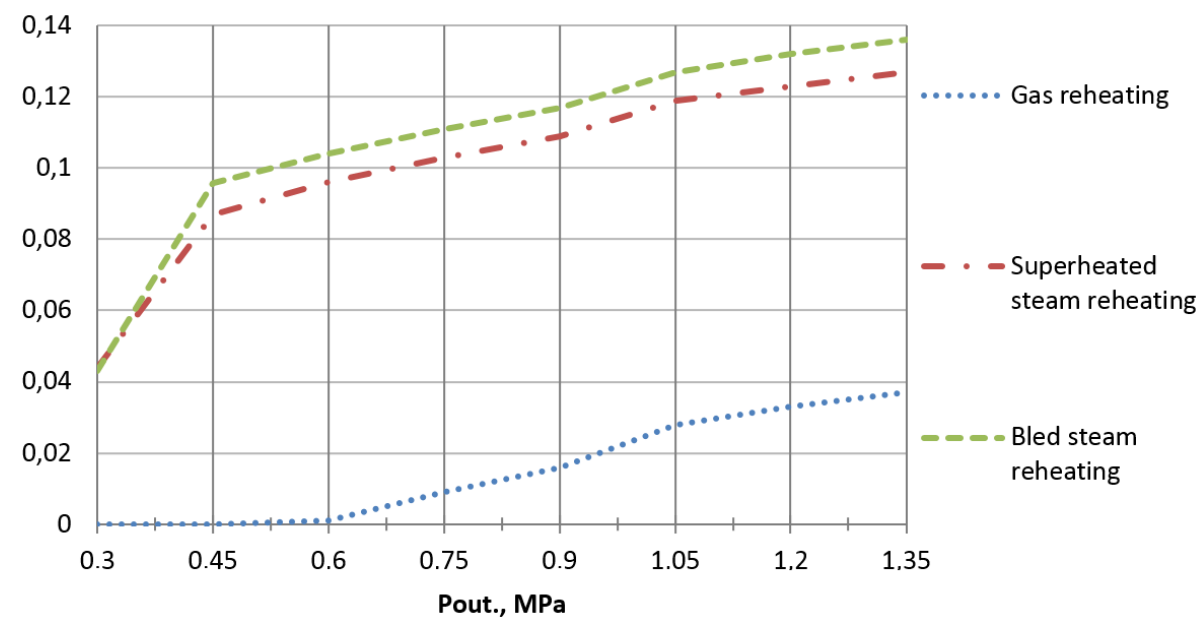

Fig. 2. Characteristic curves of final moisture content from output pressure of the high-pressure cylinder.

The characteristic curves have nonlinear dependence. With increasing of output pressure of the high-pressure cylinder, heat efficient of cycle is growing but final moisture content is increased too. The cycles have maximum efficiency at the pressure $1.35 \mathrm{MPa}$, but final moisture content is more than maximum allowed final moisture content.

\subsection{Characteristic curves of absolute efficiency ratio of cycle from number of regenerative feedwater heaters}

For impact assessment of the regenerative feedwater heating system structure the calculation was made for different number of regenerative feedwater heaters (in range from 4 to 10) for the output pressure of the high-pressure cylinder $0.75 \mathrm{MPa}$. The pressure was taken from condition of allowed final moisture content for different types of resuperheat. Thermodynamic optimum temperature of feed water was calculated with help the equation (10) and magnitude of the temperature varied in range from 207 to $303{ }^{\circ} \mathrm{C}$.

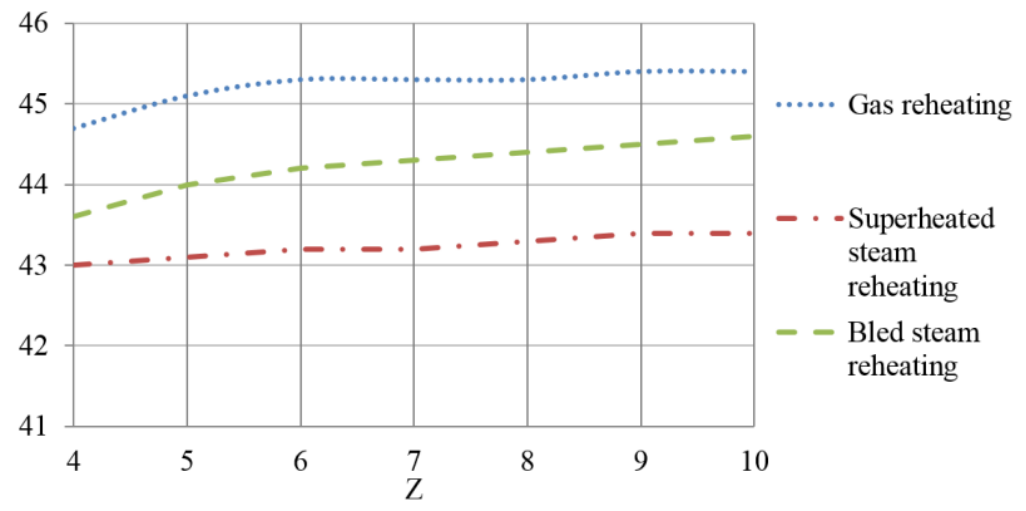

Fig. 3. Characteristic curves of absolute efficiency ratio of cycle from number of regenerative feedwater heaters.

The characteristic curves have nonlinear dependence. For "Gas" reheating and bled steam reheating the most intensive increase of absolute efficiency ratio $(0.6 \% \mathrm{abs}$. $)$ is in 
range from 4 to 6 regenerative feedwater heaters. Every next heater gives a very small increase of efficiency.

For superheated steam reheating increasing of heater number from 4 to 10 give a small increase of absolute efficiency ratio ( $0.4 \%$ abs.).

\section{Conclusion}

Results of calculation are showing that nuclear unit with steam-coolant fast neutron reactor is more efficient than widely used unit with reactor VVER. Usage of simple scheme with four regenerative feedwater heaters the absolute efficiency ratio is more than $43 \%$.

However, question about range of turbine power is open. The large value of absolute flow rates at the turbine create necessaire to calculate of admissible value range of power [2].

Goals of next experiment are size range of equipment, calculation of ejector and impact assessment of deaerator plant to thermodynamic efficient of cycle. "

\section{References}

1. D. Gvozdyakov, V. Gubin, S. Shvab, A. Tanishev, MATEC Web of Conf., 72, 01037 (2016), DOI: 10.1051/matecconf/20167201037

2. S. Lavrinenko, P. Polikarpov, A. Matveeva, V. Martyshev, MATEC Web of Conf., 110, 01049 (2017), DOI: 10.1051/matecconf/201711001049

3. E. Pavelyev, S. Lavrinenko, MATEC Web of Conf., 72, 01085 (2016), DOI: 10.1051/matecconf/20167201085

4. A.V. Vorobiev, E.M. Dutova, A.S. Latyshev, MATEC Web of Conf., 72, 01125 (2016), DOI: 10.1051/matecconf/20167201125

5. A.A. Prosvirnov, M.M. Naftal. The concept of steam-coolant fast reactor of low power. OJSC "RSRIONPP”, Moscow

6. E.V. Gukov, Power Engineering: efficiency, reliability, safety: collection of reports, 241 (2013)

7. A.M. Antonova, A.V. Vorobev, Nuclear Power Plants: study guide for discipline "Nuclear Power Plants" (TPU, Tomsk, 2009) 